\title{
Difficulty Crossing Culprit Lesion During Percutaneous Coronary Intervention
}

National Cancer Institute

\section{Source}

National Cancer Institute. Difficulty Crossing Culprit Lesion During Percutaneous

Coronary Intervention. NCI Thesaurus. Code C99946.

Placement of intracoronary devices across the coronary stenosis is troublesome or formidable. (ACC) 